\title{
Electrochemotherapy induces apoptotic death in melanoma metastases: a histologic and immunohistochemical investigation
}

This article was published in the following Dove Press journal:

Clinical, Cosmetic and Investigational Dermatology

23 November 2016

Number of times this article has been viewed

\author{
Laura Bigi' \\ Giovanna Galdo² \\ Anna Maria Cesinaro 3 \\ Cristina Vaschieri ${ }^{1}$ \\ Alessandra Marconi ${ }^{4}$ \\ Carlo Pincelli ${ }^{4}$ \\ Fabrizio Fantini ${ }^{5}$ \\ 'Department of Surgical, Medical, \\ Dental and Morphological Sciences, \\ Dermatologic Clinic University of \\ Modena and Reggio Emilia, Modena, \\ ${ }^{2}$ Plastic Surgery Unit, IRCCS-CROB, \\ Rionero in Vulture (Pz), ${ }^{3}$ Department \\ of Pathology, ${ }^{4}$ Department of Surgical, \\ Medical, Dental and Morphological \\ Sciences, Laboratory of Cutaneous \\ Biology, University of Modena and \\ Reggio Emilia, Modena, ${ }^{5}$ Dermatology \\ Unit, Azienda Ospedaliera \\ “A. Manzoni”, Lecco, Italy
}

Correspondence: Laura Bigi

Department of Surgical, Medical,

Dental and Morphological Sciences,

Dermatologic Clinic, Università di

Modena e Reggio Emilia, Via Del Pozzo,

7I 4II 24 Modena, Italy

Tel +390594224264

Fax +39059422 427I

Email laurabigi@hotmail.com
Background: Electrochemotherapy (ECT) is increasingly used in the treatment of primary and secondary skin tumors, but little is known about the pathologic mechanism responsible for tumor cell destruction in humans. Knowledge of detailed mechanism of host response after ECT may improve the treatment efficacy related to patient selection and technique refinements. Aim: The aim of the study was to investigate the histopathology and mechanism of cell death after ECT in cutaneous melanoma metastases.

Methods: Skin biopsy specimens were sequentially obtained after ECT of cutaneous melanoma metastases, during a follow-up period of 2 months. Results from histologic evaluation and immunohistochemical characterization of the inflammatory infiltrate (CD3, CD4, CD8, CD56, Granzyme-B) were compared with a panel of apoptosis-related markers.

Main outcome measures: Evidence of the mechanism of tumor cell damage, identification of histological and immunohistochemical signs of apoptosis and/or necrosis underlining a possible time course of tumor destruction and inflammatory reaction after ECT.

Results: Early signs of epidermal degeneration, an increase of the inflammatory infiltrate, and initial tumor cell morphological changes were already detected $10 \mathrm{~min}$ after ECT. The cell damage progression, as demonstrated by histological and immunohistochemical evidence using apoptotic markers (TUNEL and caspase-3 staining), reached a climax 3 days after treatment, to continue until 10 days after. Scarring fibrosis and complete absence of tumor cells were observed in the late biopsy specimens. A rich inflammatory infiltrate with a prevalence of T-cytotoxic CD3/CD8-positive cells was detected $3 \mathrm{~h}$ after ECT and was still appreciable 3 months later.

Conclusion: This study attempts to define the time course and characteristics of tumor response to ECT. The observations suggest both a direct necrotic cell damage and a rapid activation of apoptotic mechanisms that occur in the early phases of the cutaneous reaction to ECT. A persistent immune response of T-cytotoxic lymphocytes could possibly explain the long-term local tumor control.

Keywords: electrochemotherapy, melanoma, metastasis, apoptosis

\section{Introduction}

Electrochemotherapy (ECT) is a tumor ablation modality that combines cell membrane electroporation (EP) and low dosage administration of cytotoxic drugs. ${ }^{1}$ Since the early 1990s, ECT has emerged as a local treatment for superficial tumors. The efficacy of ECT was initially demonstrated in the treatment of head and neck cancers, ${ }^{2}$ and a number of investigations demonstrated its effectiveness in the treatment of several types of nodular tumor of different histology.,4 In 2006, the multicentric European Standard Operating 
Procedures of ECT study established the standard operating procedures for ECT use in the clinic. ${ }^{1}$ Currently, ECT is employed for cutaneous or subcutaneous tumor nodules of any type of cancer, both primary and metastatic, and as a palliative treatment in case of tumor bleeding or for alleviation of diseaserelated pain. ECT can also be applied as an organ-sparing treatment of non-operable primary or recurrent tumors, as well as a neoadjuvant therapy before conventional approach. ${ }^{5-9}$

The technique is based on the controlled local delivery of short and intense electric pulses that reversibly permeabilize the cell membrane barrier (EP), allowing non-permeant or low-permeant anticancer drugs (usually bleomycin) to enter the tumor cells, without affecting the surrounding normal or electrically unexposed tissues. ${ }^{1}$ Due to its mechanism of action, ECT selectively kills tumor cells without denaturing proteins. It has been proposed that ECT might allow tumor antigen shedding and local inflammation, thus attracting immune antigen-presenting cells. Therefore, an antitumor immune response, triggered by the tumor cell death, may contribute to the disease control. ${ }^{10-12}$ Even if the clinical response to ECT has now been proved on several types of skin tumors, both in humans and in animal models, still very little is known about the tissue response to ECT in vivo. This study aimed at investigating the tissue changes that occur after ECT in cutaneous melanoma metastases. Sequential biopsies were taken from treated tumor tissue. Cell damage and inflammatory response to ECT were evaluated through histological and immunohistochemical analysis, using inflammatory and apoptotic-related markers.

\section{Methods}

\section{Patients}

This study was conducted at the Dermatology Clinic, University of Modena and Reggio Emilia. Two patients with stage IIIc melanoma with multiple cutaneous metastases were selected and ECT was offered. Written informed consent was obtained before treatment. The Ethical committee of Modena approved this study. The first patient was a 79-year-old woman who had underwent surgery for a primary melanoma of the left foot, with regional lymph node metastases, 2 years before undergoing ECT. The patient had several months' history of recurrent multiple cutaneous metastases located at the left lower limb. The second patient was a 91-year-old woman with a history of primary subungual melanoma of the right fifth toe and multiple in-transit cutaneous metastases located at the right leg. In both the patients, ECT was chosen as a palliative approach to control the high number and the recurrent character of the lesions. All visible or palpable lesions in both the patients were treated in a single ECT session. Target lesions consisted of multiple, single or grouped, firm papules and nodules of different sizes.

\section{ECT treatment}

Both the patients were treated under spinal anesthesia. Because of the high number of tumor nodules, intravenous administration of bleomycin $\left(15,000 \mathrm{IU} / \mathrm{m}^{2}\right.$ in bolus) was preferred to intralesional injection. Square wave electric pulses ( 8 pulses of $1000 \mathrm{~V} / \mathrm{cm}$ amplitude, $100 \mu$ s duration at $5000 \mathrm{~Hz}$ repetition frequency) were generated and delivered to the tumor nodules using an electric pulse generator (Cliniporator; IGEA SpA, Carpi, Italy), between 8 and 28 min following bleomycin administration (an appropriate time window to successfully allow the maximum diffusion of the drug into the tissues). Complete EP of the tumor tissue was achieved through the insertion of a hexagonal array needle electrode to the nodules, including $1 \mathrm{~cm}$ safety margin. Electric pulses were applied after each insertion. The efficiency of the treatment was automatically checked and reported by the electroporator device. If necessary, several applications were performed to efficiently cover the entire tumor volume. After treatment, a dry dressing was applied.

\section{Biopsy specimens}

Sequential punch biopsy specimens were obtained under local anesthesia from cutaneous tumor nodules before ECT and at $10 \mathrm{~min}, 3 \mathrm{~h}, 3$ days, 10 days, 1 month, and 2 months after ECT. A total of 21 biopsies were processed. In the first patient, seven sequential biopsies were obtained from a single large nodule, whereas other seven sequential biopsies were taken from smaller adjacent lesions in order to minimize differences due to different anatomic sites. Seven sequential biopsies from separate adjacent lesions were taken from the right lower limb of the second patient. Routine histologic analysis was performed on formalin-fixed, paraffin-embedded, 5 - $\mu$ m-thick sections and stained with hematoxylin-eosin.

\section{Terminal Uridine deoxynucleotidyl transferase dUTP Nick End Labeling (TUNEL) staining}

TUNEL staining was performed using a commercial kit (In Situ Cell Death Detection Kit; Roche Diagnostics $\mathrm{GmbH}$, Basel, Switzerland) according to the manufacturer's instructions. Briefly, after deparaffinization and rehydration, tissue sections were treated with $20 \mathrm{mg} / \mathrm{mL}$ proteinase $\mathrm{K}$ at room temperature for $30 \mathrm{~min}$. They were then washed with phosphate-buffered saline (PBS) solution and incubated with TUNEL reaction, a solution formed by $450 \mu \mathrm{L}$ of Label Solution (fluorescein-labeled nucleotides) 
and $50 \mu \mathrm{L}$ of enzyme solution (terminal deoxynucleotidyl transferase) at $37^{\circ} \mathrm{C}$ for $60 \mathrm{~min}$ in the dark, then washed with PBS. Sections, mounted in buffered glycerin, were then analyzed using confocal microscopy (Leica TCS SP2 with AOBS, Acoustic Opto Beam Splitter; Leica, Wetzlar, Germany).

\section{Immunofluorescence}

\section{Caspase-3}

Paraffin-embedded specimens were examined by indirect immunofluorescence reaction. After deparaffinization and rehydration, tissue sections were incubated using bovine serum albumin (BSA) $0.1 \%$, then washed with PBS and incubated with antirabbit Caspase 3 active antibody (R\&D System (Minneapolis, Minnesota USA), 1:150) at room temperature for $60 \mathrm{~min}$. After washing with PBS and incubation with fluorescent antibody (antirabbit IgG, Alexa Fluor; Invitrogen, 1:200) at room temperature for $60 \mathrm{~min}$, sections were counterstained with DAPI $(0.1 \mathrm{mg} / \mathrm{mL}$, Sigma-Aldrich, Saint Louis, Missouri, USA), included in buffered glycerin, and analyzed using confocal microscopy.

\section{Immunohistochemistry}

The immunohistochemical characterization of the inflammatory infiltrate was performed with the following antibody panel: mouse monoclonal antihuman-CD20 (ab9475, Abcam, Cambridge, UK, 1:100); rabbit polyclonal antihuman CD3 (ab5690, Abcam 1:150); mouse monoclonal antihuman CD4 (ab846, Abcam 1:100); mouse monoclonal antihuman CD8 (clone C8/144B; Dako, Glostrup, Denmark,
1:100); mouse monoclonal antihuman CD56 (Dako, 1:100); antirabbit-HMB45 (polyclonal antibody; Thermo Scientific, Waltham, Massachusetts, USA, 1:200); rabbit polyclonal antihuman Granzyme-B (ab4059, Abcam 1:200). Briefly, sections were incubated for $5 \mathrm{~min}$ with a blocking solution (Ultra V Block; Laboratory Vision Corporation, Fremont, California, USA) to stop the endogenous peroxidase or alkaline phosphatase activity. After washing, sections were incubated with secondary biotinylated antibody (goat antimouse and antirabbit biotinylated antibody 1:100; BioSpa), and a streptavidin-biotin complex (streptavidin-biotinylated HRP 1:100; BioSpa, Milan, Italy) with an automated immunostainer (Benchmark; Ventana, Tucson, AZ, USA) was applied. Reaction products were finally stained with 3-amino-9-etilcarbazole and counter-stained with Mayer's hematoxylin to be visualized.

\section{Results}

\section{Patient outcomes and tumor response}

The treated lesions showed a progressive reduction of volume during the first weeks after ECT, due to gradual shrinkage and necrosis. At 2-3 months after treatment, the smaller tumor nodules were no longer detectable and replaced by slight dermal fibrosis. A partial response was also evident in the larger nodules that appeared markedly reduced in volume (Figure 1).

\section{Treatment toxicity}

No adverse events occurred during or after the ECT treatments. Postoperative pain was moderate, and analgesia was provided by paracetamol.

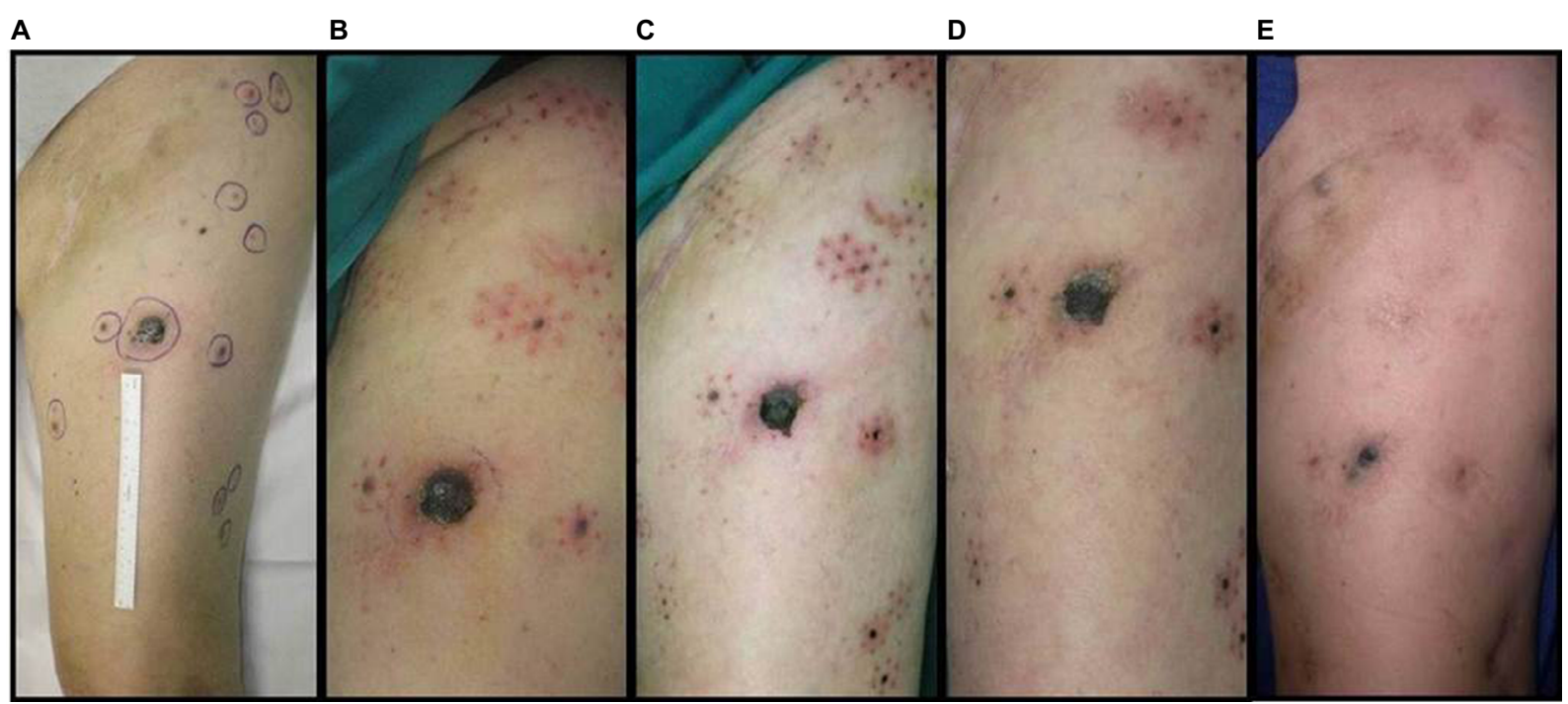

Figure I Clinical response of melanoma metastases after ECT (patient I): (A) before treatment; (B) 3 days; (C) 10 days; (D) I month; (E) 2 months. 


\section{Histologic findings}

The histopathology findings were consistent, independently of the biopsy site. Ten minutes after ECT, early signs of damage could already be detected including focal homogenization of the epidermis, increase of the inflammatory infiltrate and slight morphological alterations of tumor cells (homogeneous eosinophilic cytoplasm, chromatin clumping, and less prominent nucleoli) (Figure 2, 1B and 2B). At $3 \mathrm{~h}$ time point, the tissue damage was readily evident. The epidermis showed diffuse spongiosis, detachment from the underlying dermis and foci of cell necrosis. The dermis showed conspicuous edema, along with a massive mononuclear inflammatory infiltrate surrounding and permeating the tumor nodules. Tumor cell damage was characterized by foci of swollen cells with marked chromatin clumping, nucleo-cytoplasmic vacuolization, and loosening of cell connections. Several syncytial aggregations were detected, surrounded by the mononuclear infiltrate (Figure 2, 1C and 2C). The inflammatory response and the cell damage progressed at 3-day time, with marked nuclear deterioration, neoplastic cell fusion, and a massive inflammatory infiltrate permeating the tumor nodules (Figure 2, 2D). Scant signs of endothelial damage and fibrin deposition can be appreciated. At 10 days after ECT, advanced damage was detectable, consisting in shedding of the epidermal sheet, diffuse damage of the tumor cells with diffuse inflammatory infiltrate invading the tumor with multinuclear cell formation. The inflammatory mononuclear cells appeared extensively rimming the tumor cells as well as the degenerated cell remnants (Figure 2, 2E).

At 1 month after ECT, epidermis was completely regenerated. The dermis showed compact fibrosis in its upper part, while in the deep dermis the ratio between tumor cells and inflammatory infiltrate was completely inverted, that is, few remaining mono- or multi-nucleated tumor cells - as highlighted with the HMB45 staining - were surrounded by a dense inflammatory infiltrate (Figure $2,1 \mathrm{~F}$ and $2 \mathrm{~F}$ ). At 2 months, compact fibrosis and melanophages were present in the upper dermis, while few remaining inflammatory cells were present in the lower dermis. No tumor remnants were detected (Figure 2, $1 \mathrm{G}$ and 2G). The main histologic findings are summarized in Table 1.

\section{TUNEL and activated caspase- 3 staining}

The TUNEL reaction showed a marked positivity $3 \mathrm{~h}$ after treatment, peaking at 3 days, then returning toward base levels at 10 days and 1 month, and completely disappearing after 2 months (Figure 2, 3B-G). This suggests that an early, transient activation of the apoptotic mechanisms takes place after treatment.

Caspase-3 immunostaining paralleled the TUNEL reaction, confirming the occurrence of an apoptotic process

(1)

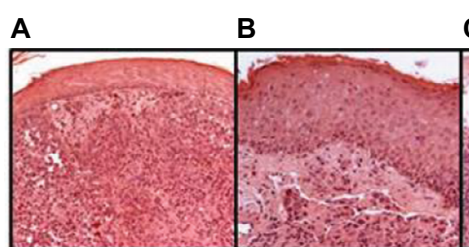

C

D

E

F

G

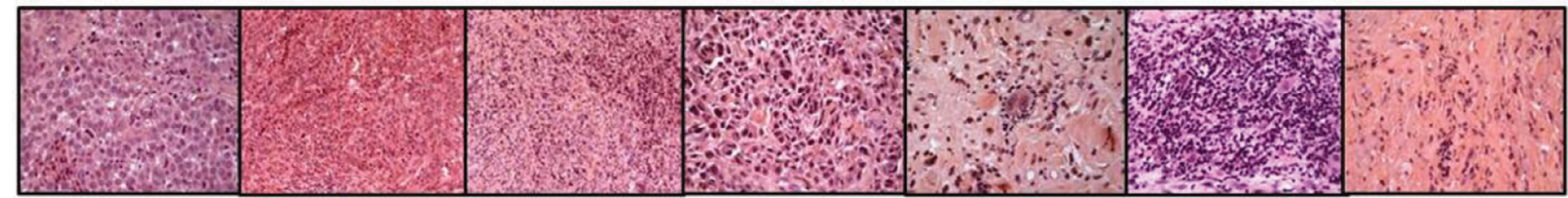

(3)

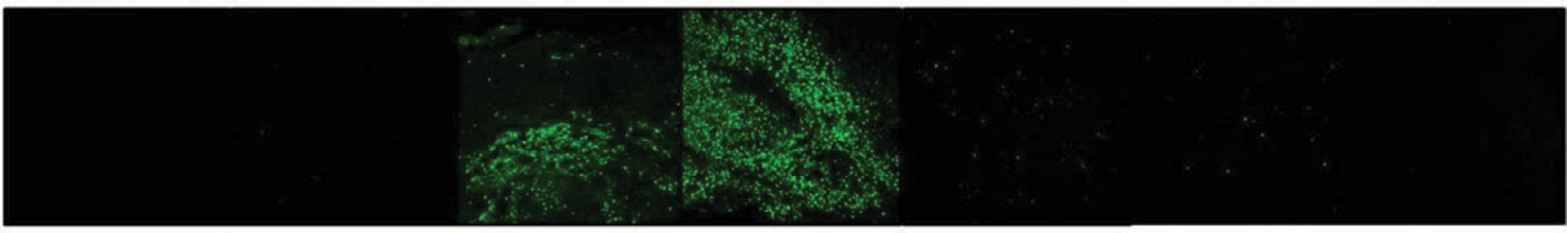

(4)

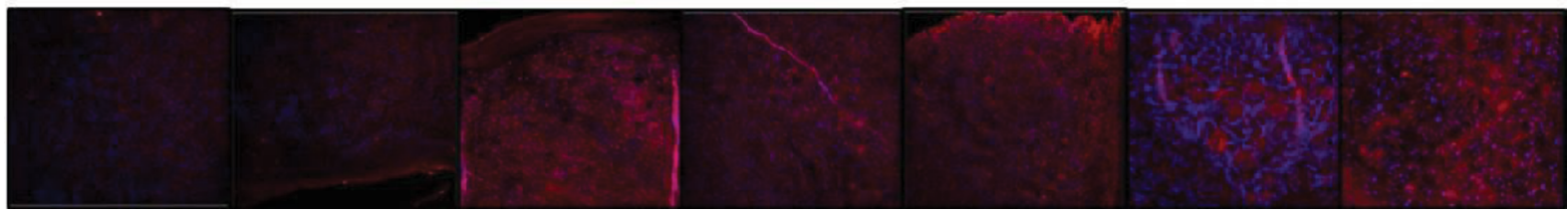

Figure 2 Time course of histological and immunohistochemical changes in cutaneous melanoma metastases after ECT. Column (A) before treatment; (B) 10 min; (C) 3 h; (D) 3 days; (E) 10 days; (F) I month; (G) 2 months. Lines: I and 2: H\&E; Line 3: TUNEL reaction; Line 4: caspase-3 staining. Line I original magnification I00×; Line 2 original magnification 250x.

Abbreviations: ECT, electro chemotherapy; H\&E, hematoxylin-eosin; TUNEL, Terminal Uridine deoxynucleotidyl transferase dot Nick End Labeling; min, minutes; h, hours. 
Table I Main histological and immunohistochemical findings after electrochemotherapy

\begin{tabular}{|c|c|c|c|c|}
\hline & Histology & TUNEL & $\begin{array}{l}\text { Activated } \\
\text { caspase-3 }\end{array}$ & Infiltrate Tipization \\
\hline 10 Min & $\begin{array}{l}\text { Initial epidermal damage (homogenization, spongiosis) } \\
\text { Dermal and intratumoral edema } \\
\text { Peri- and intratumoral inflammatory infiltrate } \\
\text { Sparse morphological alterations in tumor cells } \\
\text { (homogeneous eosinophilic cytoplasm, chromatin } \\
\text { condensation) }\end{array}$ & $\begin{array}{l}\text { Sporadic } \\
\text { positive cells }\end{array}$ & Negative & Not performed \\
\hline $3 \mathbf{H}$ & $\begin{array}{l}\text { Focal epidermal necrosis, spongiosis, junctional } \\
\text { detachment } \\
\text { Severe dermal edema } \\
\text { Marked increase of the peri- and intratumoral } \\
\text { inflammatory infiltrate } \\
\text { Foci of degenerated tumor cells (homogeneous } \\
\text { eosinophilic cytoplasm, chromatin condensation, } \\
\text { onset of syncytial aggregations) }\end{array}$ & $\begin{array}{l}\text { Increase of } \\
\text { positive cells }\end{array}$ & $\begin{array}{l}\text { Increase of } \\
\text { positive cells }\end{array}$ & $\begin{array}{l}\text { Prevalence of CD3+, } \\
\text { CD8+ cells } \\
\text { Foci of Granzyme-B+ } \\
\text { and TIA-I+ cells } \\
\text { Isolated CD56+ cells }\end{array}$ \\
\hline 3 Days & $\begin{array}{l}\text { Progressive epidermal damage } \\
\text { Massive inflammatory infiltrate both peri- and } \\
\text { intranodular with wreath-like disposition around } \\
\text { multinucleate cells } \\
\text { Progression of degenerated tumor cell foci } \\
\text { Several syncytial aggregations }\end{array}$ & $\begin{array}{l}\text { Extensive } \\
\text { presence of } \\
\text { positive cells in } \\
\text { tumor nodules }\end{array}$ & $\begin{array}{l}\text { Extensive presence of } \\
\text { positive cells in tumor } \\
\text { nodules }\end{array}$ & $\begin{array}{l}\text { Increased prevalently } \\
\text { CD8+ infiltrate with } \\
\text { perinodular and } \\
\text { pericellular disposition } \\
\text { (rimming) } \\
\text { Granzyme-B+ cells } \\
\text { Spare CD56+ cells }\end{array}$ \\
\hline 10 Days & $\begin{array}{l}\text { Epidermal necrosis } \\
\text { Massive inflammatory infiltrate } \\
\text { Several multinucleated tumor cells rimmed by } \\
\text { lymphocytes } \\
\text { Initial fibrosis and vascular damage }\end{array}$ & $\begin{array}{l}\text { Sporadic } \\
\text { positive cells }\end{array}$ & Several positive cells & $\begin{array}{l}\text { CD8+ infiltrate with } \\
\text { pericellular disposition } \\
\text { (rimming) } \\
\text { Granzyme-B+ cells }\end{array}$ \\
\hline I Month & $\begin{array}{l}\text { Regenerated epidermis } \\
\text { Residual tumor cells in the deep dermis (HMB45+), } \\
\text { with massive lymphocytic infiltrate } \\
\text { Increased fibrosis in the superficial dermis }\end{array}$ & $\begin{array}{l}\text { Sporadic } \\
\text { positive cells }\end{array}$ & $\begin{array}{l}\text { Diffuse syncytial } \\
\text { positive cells }\end{array}$ & $\begin{array}{l}\text { Rich CD8+ infiltrate } \\
\text { still affects few residual } \\
\text { tumor cells } \\
\text { Granzyme-B+ cells } \\
\text { Spare CD56+ cells }\end{array}$ \\
\hline 2 Months & $\begin{array}{l}\text { Dermal fibrosis } \\
\text { Numerous melanophages } \\
\text { Complete disappearing of tumor cells } \\
\text { Residual focal lymphocytic infiltrate }\end{array}$ & Negative & Negative & $\begin{array}{l}\text { Residual CD8+ } \\
\text { infiltrate }\end{array}$ \\
\hline
\end{tabular}

Abbreviations: Min, minutes; $\mathrm{H}$, hours.

triggered by enzymatic activation. Activated caspase- $3+$ cells were detected in the tumor nodules $3 \mathrm{~h}$ after ECT. These cells increased at 3 and 10 days. After 1 and 2 months, caspase- 3 positivity was still appreciated in the cytoplasm of the mono/ multinucleated cells within the tumor mass (Figure 2, 4B-G).

\section{Inflammatory infiltrate}

The immunohistochemical analysis of the inflammatory infiltrate showed a striking prevalence of CD3+ T lymphocytes in all stages of the tissue reaction after ECT. No CD20+ B cells were detected. The infiltrate consisted largely of CD8+ cells, whereas CD4+ lymphocytes were scant. In particular, the inflammatory cells rimming the tumor cells, both single and multinucleated, as well as the tumor cell remnants, were exclusively composed of CD8+ lymphocytes expressing Granzyme-B (Figure 3A and B). Foci of CD56+ (NK) cells were present, interspersed within the tumor nodules, beginning at $3 \mathrm{~h}$ and still detected at 1 month after treatment. These findings demonstrate that cytotoxic/suppressor cells are activated early after ECT treatment, are in close contacts with apoptotic tumor cells, and represent the key elements in the late inflammatory response. Results of the immunohistochemical analysis are summarized in Table 1.

\section{Discussion}

Several clinical studies have demonstrated the safety and efficacy of ECT in the tumor control of a wide range of primary and metastatic malignancies..$^{6-8,13}$ In particular, ECT has been shown to be a safe and effective treatment option in a palliative setting for melanoma cutaneous and subcutaneous metastases. ${ }^{14-16}$ Early studies showed that the ECT effectiveness was linked to the combination of chemotherapeutic 


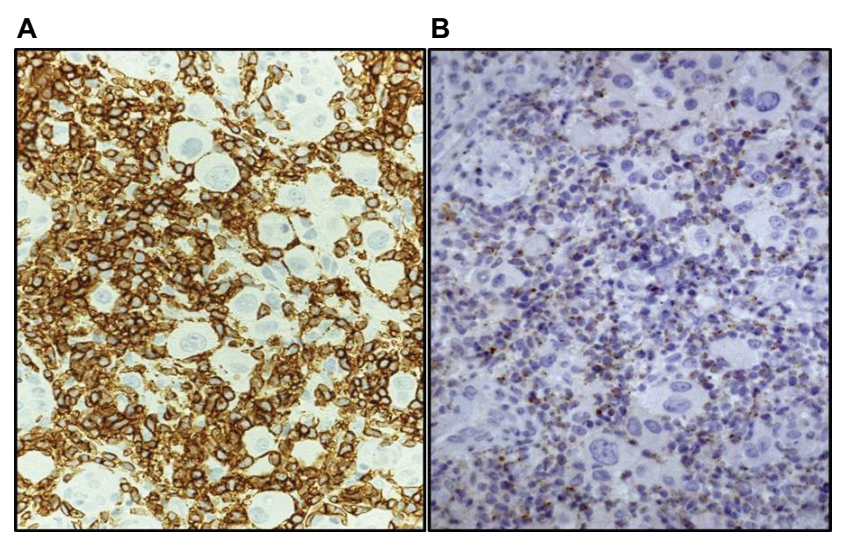

Figure 3 Immunohistochemical characterization of the inflammatory infiltrate surrounding tumor cells at I month (A) CD8 and (B) Granzyme-B.

drug injection and locally applied electric pulses, because either component, alone, was ineffective. The effect of ECT on tumor tissue may be related to a combination of different components: the direct cell damage caused by the cytotoxic activity of bleomycin molecules that have entered the cell through the electroporated cell membrane and the indirect damage by vascular effects and/or immuno-inflammatory reactions. ${ }^{10,11,17}$ In vitro and in vivo studies suggested triggering of apoptosis as a prevalent mechanism in the direct tumor cell damage. ${ }^{18,19}$ In humans, evidence of a prevalent mechanism operating in vivo is lacking. To highlight the pathways of ECT action in vivo, this study investigated the alterations in cutaneous melanoma metastases treated with ECT through sequential histologic and immunohistochemical analysis. The apoptotic markers caspase-3 and TUNEL were used along with histological evaluation. The results help to define the time course and characteristics of the tumor response to ECT.

ECT induces an early intense damage to the tumor cells. The histologic signs of cell injury (swollen cells with homogeneous eosinophilic cytoplasm, chromatin condensation, less prominent nucleoli) can be detected as early as 10 min after treatment. They increase progressively during the following days, leading finally to a complete destruction of tumor nodules that in our cases was evident 2 months after therapy. A distinctive sign of melanoma cell damage after ECT is the progressively increasing number of multinucleated syncytial cells. These cells may result from an in vivo electrofusion induced by EP, as demonstrated in an experimental tumor model in mice (B16 melanoma). ${ }^{20}$ In this model, syncytial cell formation was an early $(1 \mathrm{~h})$ event after EP, and was melanoma-specific, as it did not occur in normal tissue or in another tumor type (LPB fibrosarcoma). Morphological and immunohistochemical evidence of apoptosis was detected in the multinucleated cells. In our model, we could detect the appearance of syncytial aggregations as early as $3 \mathrm{~h}$ after ECT, and multinucleated apoptotic (caspase-3 positive) cells were still present after 1 month. The TUNEL reaction and the caspase-3 staining, hallmarks of apoptosis, paralleled the histological signs of damage, peaking at 3 and 10 days after ECT, then gradually reverting toward base levels. The consistency of histological and immunohistochemical findings strongly supports the assumption of an apoptotic cell death. In a mouse model, involving treatment of experimentally injected melanoma lines using an association of low electric field and chemotherapy, also a transient ( $3-4 \mathrm{~h}$ ) apoptotic phase, as detected by morphologic (swollen cells with condensed nuclei) and immunohistochemical observations, was demonstrated. The apoptotic step was followed by massive necrosis of the tumors at 48-72 h. ${ }^{21}$ In rats, hepatocellular carcinoma nodules treated with ECT showed morphologic signs of apoptosis decreasing from day 3 to day 14 . No sign of apoptosis was seen at day 21 , when tumor nodules appeared completely necrotic. ${ }^{22}$ An in vitro study by Tounekti et al showed that the mechanisms of the cell death caused by bleomycin were closely related to the number of bleomycin molecules introduced into the cell cytoplasm. When only a few thousand molecules were internalized, cells displayed an arrest in the G2-M phase of the cell cycle paralleling the "mitotic death" seen after ionizing irradiation. By contrast, the introduction of high amounts of molecules into the cell cytoplasm by electropermeabilization induced events analogous to those observed during apoptosis (cell shrinkage, membrane blebbing, reduced cell fluorescence, and inter nucleosomal DNA fragmentation), so bleomycin could be considered an apoptosis mimetic drug. ${ }^{18}$

An experimental model in mice, analogous to our therapeutic situation, was carried on by Mekid et al, ${ }^{23}$ and likewise, they observed two different cell death pathways in melanomabearing mice treated with bleomycin and EP, depending on the bleomycin dose utilized. At low dose, a mitotic cell death pathway was characterized by the appearance of atypical mitoses (TUNEL and caspase-3 positive) followed by typical apoptotic cells. At high doses, a pseudoapoptotic pathway was detected, that is, the rapid appearance of apoptotic morphological changes due to the bleomycin-induced generation of double-strand DNA breaks without the intervention of the cell enzymatic processes. In the therapeutic setting, it is likely that different tumor cell death mechanisms are operating, nevertheless the positivity of caspase- 3 staining indicates that at least a fraction of the tumor cells undergoes a true apoptotic process.

Ischemic damage has been promoted as a possible mechanism of cell damage after ECT. A transient decrease in blood 
flow is a physiological reaction of the tissues exposed to electric pulses. Interestingly, it has been shown that in tumors the vasoconstriction (vascular lock) is much more longer than in normal tissues. ${ }^{24,25}$ These modifications in blood flow could be therapeutically advantageous, decreasing the drug wash-out in tumoral nodules. Moreover, damage to endothelial cells has been observed. ${ }^{10,17}$ ECT has been demonstrated to have direct vascular disrupting action on the tumor blood vessels. A study by Markelc et al showed the in vivo response of tumor and normal blood vessels to ECT at a single blood vessel level. In the tumors treated with ECT, there was no blood flow detected even $24 \mathrm{~h}$ after the therapy, indicating that the cytotoxic effect of ECT on tumor endothelial cells probably destroys the tumor blood vessels, leading to ischemic death of the cells. In a clinical setting, this effect results in an immediate and prolonged cessation of bleeding followed by crust formation. Of outmost importance is also the fact that the normal blood vessels surrounding the tumor were not destroyed after ECT and retained their functionality after the therapy confirming that the selective action by ECT on tumor vasculature. ${ }^{25,26}$

In the specimens of this study, vasodilation was observed as result of the acute inflammation, and neoangiogenesis in the late phases, but histologic sign of vascular damage was scant and limited to the endothelial cells and to fibrin deposition in the 3- and 10-day specimens.

Apoptotic cell destruction may favor the development of an antitumor immune response. Both enhanced exposure of tumor-associated antigens and better accessibility of immune cells to tumor antigens may explain this effect. In our study, the early appearance and the progressive increase of the inflammatory infiltrate, which mirrors the gradual reduction of the tumor mass, underscore the heavy participation of the immune-inflammatory system in the tissue events subsequent to ECT. The characterization of the inflammatory infiltrate showed a substantial presence of CD8+ lymphocytes that infiltrated and surrounded the tumor cells from the earliest phases to the late stages. Persistent CD8+ cells were present 2 months after ECT, when more tumor cells could not be detected. Expression of Granzyme-B, the lymphocytic cytotoxic protein that activates the apoptotic mechanism, was detected in the CD8+ cells. A NK cell response was also present, detectable as early as $3 \mathrm{~h}$ after treatment. No signs of participation of other immune cell types were found. Our observation is in line with previous experimental studies that showed infiltration of inflammatory cells 7 days after the third run of ECT in mice. ${ }^{27}$ In another study, a massive infiltration of T cells and macrophages into the tumor was appreciated at 48-72 $\mathrm{h}$ after low electric field-enhanced chemotherapy of melanoma in mice. ${ }^{21}$ An investigation focused on the analysis of the inflammatory infiltrate in tumor-bearing mice after ECT, demonstrating an early recruitment of antigen-presenting dendritic cells, followed by the later (72-96 h) appearance of CD8+ lymphocytes. ${ }^{28}$ Local infiltration and activation of epidermal (Langerhans cells) and dermal dendritic cells have been shown also in melanoma metastases after therapeutic ECT. ${ }^{12}$ In humans, the antitumor cytotoxic $\mathrm{T}$ lymphocyte responses against known tumor antigens were investigated by Andersen et $\mathrm{al}^{29}$ in melanoma patients over the course of IL-2-based ECT. The authors found a statistically significant decline in the amount of tumor-specific $\mathrm{T}$ cells in peripheral blood during therapy, followed by a statistically significant reappearance of the $\mathrm{T}$ cells upon interruption of IL-2 administration. These data strengthen the notion that IL-2 adds to the capacity of activated T cells to leave the blood stream and home to the tumor site. Molecular analyses of the clonotypic composition of responding $\mathrm{T}$ cells demonstrated that new clones emerged over the course of treatment. The authors suggest that the extensive tumor cell death elicited by the ECT may attract dendritic cells that capture exogenous tumor antigen, subsequently migrate to the draining lymph nodes and initiate T-cell responses against tumor antigens. ${ }^{29}$ Dendritic cells can efficiently prime melanoma-specific CD8+ lymphocytes, stimulating their migration to the inflamed skin. ${ }^{30}$ Even if a persistent inflammatory reaction was evident after ECT, with a massive participation of CD8+/Granzyme-B+ cells in the same areas where tumor cell death is evident, the present model does not allow to reach conclusive evidence of a contribution of these immune cell/tumor cell interactions to the activation of the apoptotic mechanisms and to the local tumor destruction. Pioneer studies investigated the participation of the immune system to ECT responses in experimental animal models, demonstrating that a normal immune system is required for the complete tumor eradication. ${ }^{31}$ The enhancement of the local and systemic antitumor effects by the combination of ECT with adjuvant immunotherapy substantiated these findings. ${ }^{32}$ Later, it was demonstrated that specific cytotoxic T-lymphocyte responses, as evaluated with the chromium radioisotope ${ }^{51} \mathrm{Cr}$ release assay, can be induced in the spleen of mice after ECT treatment of experimental colorectal carcinoma. Tumor development from cancer cell reinjection was hampered in survived animals. Thus, ECT seems to confer protective immunity toward experimental tumor re-challenge. ${ }^{33}$ These results were confirmed in melanoma-bearing mice that showed protection toward tumor reinjection after ECT treatment. This resistance could be 
reversed with the immunosuppressive drug cyclosporin A. Furthermore, the splenocytes of cured animals show antitumor activity in a Winn assay and increased level of several cytokines m-RNA expression (IL-2, IL-4, and IFN $\gamma$ ) ${ }^{21}$ Additional studies confirmed that repeated ECT sessions elicit tumor regression in immunocompetent mice inoculated with colon carcinoma cell lines. The same effect was not seen in nude mice, supporting once more the concept that an efficient immune response is required to obtain a complete therapeutic effect. ${ }^{27,34}$ Finally, more findings showed that stimulation of dendritic cells with toll-like receptor-9 ligands greatly enhances the systemic antitumor immune response after ECT and that this response is mediated by CD8+ lymphocytes, which are expanded and activated both locally (draining lymph nodes) and systemically (spleen). ${ }^{28}$

\section{Conclusion}

ECT is a very efficient local anticancer treatment for superficial lesions and possibly for deeper tumors. Although ECT is highly efficient on locally treated nodules, it appears to have no antitumor effects on nontreated distant nodules. Even though ECT shows immunostimulating properties through immunogenic cell death elicitation, the antitumor immune responses are not strong enough to destroy fully established distant tumors. Interestingly preliminary data sustain the use of ECT in association with systemic immune checkpoint inhibitors, such as anticytotoxic $\mathrm{T}$ lymphocyte-associated antigen-4 or antiprogrammed cell death protein 1 antibodies. The combined concept of local therapy with systemic immune checkpoint inhibition is currently being studied in prospective clinical trials and has the potential to further improve the success of cancer immunotherapy. ${ }^{35,36}$

\section{Disclosure}

The authors report no conflicts of interest in this work.

\section{References}

1. Mir LM, Gehl J, Sersa G, et al. Standard operating procedures of the electrochemotherapy: instructions for the use of bleomycin or cisplatin administered either systemically or locally and electric pulses delivered by the Cliniporator by means of invasive or non-invasive electrodes. EJC Suppl. 2006;4:14-25.

2. Belehradek M, Domenge C, Luboinski B, Orlowski S, Belehradek J Jr, Mir LM. Electrochemotherapy, a new antitumor treatment. First clinical phase I-II trial. Cancer. 1993;72:3694-3700.

3. Rudolf Z, Stabuc B, Cemazar M, Miklavcic D, Vodovnik L, Sersa G. Electrochemotherapy with bleomycin: the first clinical experience in malignant melanoma patients. Radiol Oncol. 1995;29:229-235.

4. Glass LF, Fenske NA, Jaroszeski M, Perrott R, Harvey DT, Reintgen DS, Heller R. Bleomycin-mediated electrochemotherapy of basal-cell carcinoma. J Am Acad Dermatol. 1996;34:82-86.

5. Sersa G. The state-of-the-art of electrochemotherapy before the ESOPE study; advantages and clinical uses. EJC Suppl. 2006;4:52-59.
6. Bertino G, Sersa G, De Terlizzi F, et al. European research on electrochemotherapy in head and neck cancer (EURECA) project: results of the treatment of skin cancer. Eur J Cancer. 2016;63:41-52.

7. Matthiessen LW, Chalmers RL, Sainsbury DC, et al. Management of cutaneous metastases using electrochemotherapy. Acta Oncol. 2011;50(5):621-629.

8. Campana LG, Testori A, Curatolo P, et al. Treatment efficacy with electrochemotherapy: a multi-institutional prospective observational study on 376 patients with superficial tumors. Eur J Surg Oncol. Epub 2016 Jun 29.

9. Matthiessen LW, Johannesen HH, Hendel HW, Moss T, Kamby C, Gehl J. Electrochemotherapy for large cutaneous recurrence of breast cancer: a phase II clinical trial. Acta Oncologica. 2012;51:713-721.

10. Mir LM. Bases and rationale of the electrochemotherapy. EJC Suppl. 2006;4:38-44.

11. Reinhold U. Electrochemotherapy for primary skin cancer and skin metastasis related to other malignancies. Anti-Cancer Drugs. 2011;22:711-718.

12. Gerlini G, Sestini S, Di Gennaro P, Urso C, Pimpinelli N, Borgognoni L. Dendritic cells recruitment in melanoma metastasis treated by electrochemotherapy. Clin Exp Metastasis. 2013;30(1):37-45.

13. Spratt DE, Gordon Spratt EA, Wu S, DeRosa A, Lee NY, Lacouture ME, Barker CA. Efficacy of skin-directed therapy for cutaneous metastases from advanced cancer: a meta-analysis. JClin Oncol. 2014;32(28):3144-3155.

14. Marty M, Sersa G, Garbay GR, et al. Electrochemotherapy - an easy, highly effective and safe treatment of cutaneous and subcutaneous metastases: results of ESOPE (European Standard Operating Procedures of Electrochemotherapy) study. EJC Suppl. 2006;4:3-13.

15. Campana LG, Testori A, Mozzillo N, Rossi CR. Treatment of metastatic melanoma with electrochemotherapy. J Surg Oncol. 2014;109(4): 301-307.

16. Solari N, Spagnolo F, Ponte E, et al. Electrochemotherapy for the management of cutaneous and subcutaneous metastasis: a series of 39 patients treated with palliative intent. J Surg Oncol. 2014;109(3):270-274.

17. Jarm T, Cemazar M, Miklavcic D, Sersa G. Antivascular effects of electrochemotherapy: implications in treatment of bleeding metastases. Exp Rev Anticancer Ther. 2010;10(5):729-746.

18. Tounekti O, Pron G, Belehradek J Jr, Mir LM. Bleomycin, an apoptosis-mimetic drug that induces two types of cell death depending on the number of molecules internalized. Cancer Res. 1993;53(22): $5462-5469$.

19. Tounekti O, Belehradek J Jr, Mir LM. Relationships between DNA fragmentation, chromatin condensation, and changes in flow cytometry profiles detected during apoptosis. Exp Cell Res. 1995;217(2):506-516.

20. Mekid H, Mir LM. In vivo cell electrofusion. Biochim Biophys Acta. 2000;1524 (2-3):118-130.

21. Entin I, Plotnikov A, Korenstein R, Keisari Y. Tumor growth retardation, cure, and induction of antitumor immunity in B16 melanoma-bearing mice by low electric field-enhanced chemotherapy. Clin Cancer Res. 2003;9:3190-3197.

22. Jaroszeski MJ, Coppola D, Pottinger C, Benson K, Gilbert RA, Heller R. Treatment of hepatocellular carcinoma in a rat model using electrochemotherapy. Eur J Cancer. 2001;37:422-430.

23. Mekid H, Tounekti O, Spatz A, Cemazar M, El Kebir FZ, Mir LM. In vivo evolution of tumour cells after the generation of double-strand DNA breaks. Br J Cancer. 2003;88(11):1763-1771.

24. Sersa G, Cemazar M, Miklavcic D, Chaplin DJ. Tumor blood flow modifying effect of electrochemotherapy with bleomycin. Anticancer Res. 1999; 19(5B):4017-4022.

25. Markelc B, Sersa G, Cemazar M. Differential mechanisms associated with vascular disrupting action of electrochemotherapy: intravital microscopy on the level of single normal and tumor blood vessels. PLoS One. 2013; 8(3):e59557.

26. Gehl J, Geertsen PF. Efficient palliation of haemorrhaging malignant melanoma skin metastases by electrochemotherapy. Melanoma Res. 2000; 10(6):585-589.

27. Gunji Y, Uesato M, Miyazaki S, et al. Generation of antitumor autoimmunity against large colon tumor by repeated runs of electrochemotherapy. Hepatogastroenterology. 2005; 52(63):770-774. 
28. Roux S, Bernat C, Al-Sakere B, et al. Tumor destruction using electrochemotherapy followed by $\mathrm{CpG}$ oligodeoxynucleotide injection induces distant tumor responses. Cancer Immunol Immunother. 2008; 57(9):1291-1300.

29. Andersen MH, Gehl J, Reker S, Pedersen LØ, Becker JC, Geertsen P, thor Straten P. Dynamic changes of specific T cell responses to melanoma correlate with IL-2 administration. Semin Cancer Biol. 2003; 13(6): 449-459.

30. Salio M, Cella M, Vermi W, et al. Plasmacytoid dendritic cells prime IFN-gamma-secreting melanoma-specific CD8 lymphocytes and are found in primary melanoma lesions. Eur J Immunol. 2003; 33(4): 1052-1062.

31. Sersa G, Miklavcic D, Cemazar M, Mir LM. Electrochemotherapy with CDDP on LPB sarcoma: comparison of the anti-tumor effectiveness in immunocompetent and immunodeficient mice. Bioelectrochem Bioenerg. 1997; 43:279-283.
32. Mir LM, Orlowski S, Poddevin B, Belehradek J Jr. Electrochemotherapy tumor treatment is improved by interleukin-2 stimulation of the host's defenses. Eur Cytokine Netw. 1992; 3(3):331-334.

33. Kuriyama S, Mitoro A, Tsujinoue H, et al. Electrochemotherapy can eradicate established colorectal carcinoma and leaves a systemic protective memory in mice. Int J Oncol. 2000; 16:979-998.

34. Miyazaki S, Gunji Y, Matsubara H, et al. Possible involvement of antitumor immunity in the eradication of colon 26 induced by low-voltage electrochemotherapy with bleomycin. Surg Today. 2003; 33(1):39-44.

35. Calvet CY, Mir LM. The promising alliance of anti-cancer electrochemotherapy with immunotherapy. Cancer Metastasis Rev. 2016; 35(2): 165-177.

36. Theurich S, Rothschild SI, Hoffmann M. Local tumor treatment in combination with systemic ipilimumab immunotherapy prolongs overall survival in patients with advanced malignant melanoma. Cancer Immunol Res. 2016; 4(9):744-754.
Clinical, Cosmetic and Investigational Dermatology

\section{Publish your work in this journal}

Clinical, Cosmetic and Investigational Dermatology is an international, peer-reviewed, open access, online journal that focuses on the latest clinical and experimental research in all aspects of skin disease and cosmetic interventions. This journal is included on PubMed. The manuscript management system is completely online

\section{Dovepress}

and includes a very quick and fair peer-review system, which is all easy to use. Visit http://www.dovepress.com/testimonials.php to read real quotes from published authors 